\title{
Operating Models of Chinese Agricultural Cold Chain Based on System Dynamics
}

\author{
Xin Shen ${ }^{1}$, Qiao Liu ${ }^{2,3}$ and Dawei Zhao ${ }^{2}$ \\ ${ }^{1}$ College of Economics and Management, Shanghai Ocean University, Shanghai, \\ 201306, China \\ ${ }^{* 2}$, Management School, Harbin University of Science and Technology, Harbin, \\ Heilongjiang, 150080 ,China; \\ ${ }^{3}$, College of Economics and Management, Heilongjiang Institute of Technologies, \\ Harbin, Heilongjiang, 150050,China \\ 1,xshen@shou.edu.cn;2,qiao1027@126.com;3,dwzhao2012@126.com
}

\begin{abstract}
This study aims to establish current main Chinese agricultural-product cold chain (ACC) models and compare the efficiency based on system dynamic analysis. In China, the operating model for ACC falls into three categories, namely, SWR model (wholesaler dominant), SS (supermarket dominant) and SDC (supplier dominant). We analyze the three models' framework and relevant practices in China, particularly describe detailed flowcharts of SWR model and SS model because SDC model is not yet mature in China. Based on the two models, we apply system dynamics theory to compare the bullwhip effects and relevant inventory level of them under stochastic demand information. Simulation results show that comparing with SWR model, SS model has competitive advantages in lower inventory, less fluctuation and bullwhip effect. Thus agricultural product cold chain driven by retailers (supermarkets) proves to be more efficient and cost-effective.
\end{abstract}

Keywords: Cold Chain; Operating Model; System Dynamics; Bullwhip Effect

\section{Introduction}

China has vast territory, different geographical location of produce and difference of regional resources endowment have important influence on the formation of agricultural products logistics and supply chain. Perishable produce as meat, poultry, aquatic products, vegetables, fruits, eggs from the origin of harvest or slaughter, fishing, would go through relevant product processing, packaging, storage, transportation, distribution, retailing, and other links and then reach the hands of consumers.

For a long time, because of the lack of efficient cold chain logistics process, Chinese agricultural postpartum loss are serious, and frequent food safety accidents occur. Take circulation corrosion loss rates of fruits/vegetables, meat, and aquatic products as example, they respectively reached $30 \%, 12 \%$ and $12 \%$, according to the official survey by National Development and Reform Commission of China. Especially annual loss of fruits and vegetables is estimated to as huge as 15 billion dollars above [1]. Agricultural product fluctuation, as this argument goes, is not just a problem of the farmers who is the subject of production [2], but has much close relationship with the whole supply and demand chain.

Meanwhile, with the advancement of residents' income and sense of life quality, the demand of fresh and safe produce has increased. Therefore, how to operate an 
efficient and cost-effective agricultural product cold chain (ACC) has become a hot issue of the whole society in China.

The perspective of ACC may well be a useful organization method to regulate circulation of fresh items [3]. According to the definition of logistics and supply chain from the Council of Supply Chain Management Professionals (CSCMP), we tend to propose the definition of ACC: ACC encompasses the planning and management of all activities involved in sourcing and procurement, conversion, and all logistics management activities of the perishable produce under suitable condition for the purpose of meeting customers' demand.

More importantly, ACC also includes coordination and collaboration with channel partners, which can be a chain structure with suppliers like farmers, intermediaries like processing companies, wholesalers and all sorts of retailing terminals, third party service providers like logistics companies, and the end customers. An efficient operation of ACC would be good at planning, implementing and controlling the flow and storage of fresh produce, service and related information from a point of origin to a point of consumption, say, from farmland to dining table.

Like supply chain of non-perishable items, there are core enterprises in ACC, which could be any members in the chain. However, as far as current China concerned, few efficient ACC has taken shape, which fail to exert quick response strategy to meet the consumers' demands [4]. Some scholars [5-6] assert ACC based on the core leadership of supermarkets, in this model, terminal retailers such as supermarkets or food markets would proactively seek to cooperate with fewer and strategic suppliers in order to maintain a stable relationship. This model is partly proved its efficiency of timeliness [6]. Also some literature focusses on system dynamics or game theories to analyze complicated systems including supply chain [7,8], their results direct to an important observing indicator, inventory level of the chain, in which bull-whip effect take on and we would like to shed light on the referent.

The best way to solve the bullwhip effect is to shorten the whip, and then such changes also will be small [9]. Through efficient supply chain management system, bull-whip effect can be reduced, directly minimizing the operating costs of enterprises to achieve the ideal of real-time response to customer demand [10].

Similarly, efficient integration of ACC solution is considered to be the most effective weapon. But some traditional operation models have to be changed to achieve such efficiency. We believe that the key problem is not lying on how many cold facilities are applied but how they are organized and operated for the cold chain, especially on the distribution and inventory management methods. In this study, we aim to apply systematic dynamics theory to analyze the operation models of ACC as it has the recognized basic characteristics of complexity and dynamics. Before that, we would describe the relationship of different inventory levels and random demand information according to different models in order to determine which model is comparatively efficient and effective.

\section{Primary Models of ACC}

Before analyzing the systematic dynamics of ACC, it is necessary to shed light on the primary models in China. Currently, Chinese ACC has three primary models in which key chain member dominate chain efficiency.

The first model is called SWR model, where $\mathrm{S}, \mathrm{W}$ and $\mathrm{R}$ respectively means suppliers, wholesalers and retailers. This model is controlled by the middle link, say, wholesalers. The second one is named as "SR model", where S and R are the abbreviation of suppliers and retailers, in which the supplier is subordinated to the retailer. The third one is SC model, where $\mathrm{S}$ represents supplier and $\mathrm{C}$ means consumers. 


\subsection{SWR Model}

SWR model consists of the farmer, processor, wholesaler, retailer and consumer from the point of origin to the point of consumption ${ }^{[11,12]}$. Here, we deem the farmer and processor as the supplier. This traditional operation model is most common in China. In this model, there is an invisible hand of market mechanism to regulate demand and supply. From the view of supply chain management, though wholesalers stand at the key position of the entire chain in this model, all chain members still work for themselves, which makes hard to organize the entire chain as an integrated one. Figure 1 demonstrates the model in detail.

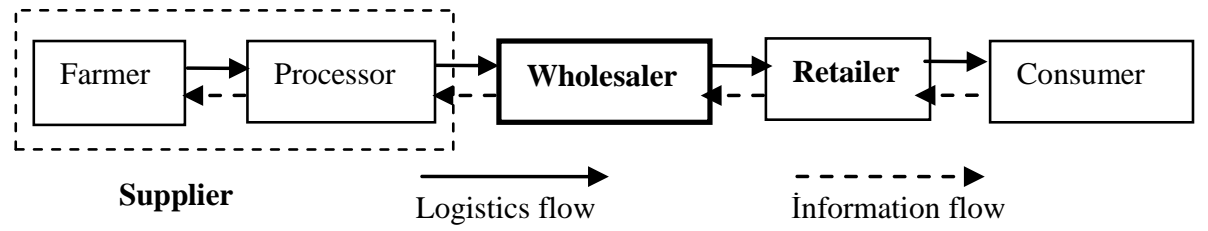

Figure 1. The SWR Model of ACC

From the figure 1, we can find that as dominant link in the chain, wholesalers integrate the cold chain supply information of agricultural products from suppliers which encompass farmers and/or processors with downstream demand information from retailers which pass values to consumers.

For all suppliers, wholesales are termination of information, and for downstream retailers, they are suppliers. In China, these wholesalers play great role in circulation of produce, especially for the citizens. Due to historical reason beginning from the centralplanning system, wholesalers cluster into various markets. Thirty years ago, all these markets and wholesalers were operated by state, these collecting and distributing function made wholesalers intensify their roles in produce circulation. Even today, nearly all markets and most wholesalers belong to private economy entities, their accumulated role still impact China and keep much powerful in market as well as the majority of the agents in circulation.

Take Shandong Shouguang Vegetable Wholesale Market (SSVWM) as example, it, founded in 1984, is famous for its big scale, high quality, all varieties across China. Market area of $667,000 \mathrm{~m}^{2}$, clinch a deal in 10 billion $\mathrm{kgs}$ of vegetables and turnover of more than 16 billion US. Dollars. There are more than 300 varieties of listed vegetables from more than 20 provinces in China all the year in the trade. SSVWM is China's largest distribution center of vegetables, price forming center, information exchange center and distribution center. Due to historical habitual thinking, suppliers such as processor or farmers tend to look for the existing wholesale markets like SSVWM rather than the end user. Admittedly, inertial thinking method inhibits suppliers' drive to realize the delivery to "the last kilometer". Meanwhile, wholesalers invest loads of capital in cold chain facilities including refrigerators, chill cars, cold logistics information systems; all of these intensify its position.

\subsection{SS Model}

SS model of ACC is the emerging phenomenon of produce circulation in China. In this model, the dominant position of wholesalers in SWR model is replaced by supermarkets (retailers) in the cold chain.

As demonstrated from Figure 2, there is no wholesalers in the chain, which means that duo to development in the market economy, ambitious supermarkets overlook the 
redundant link and order the produce directly from source of origin, even some of them tend to customize their orders with the farmers or processors.

From the supply chain management point, as the lack of intermediary link of wholesalers, the information flow and logistic lead time would be decreased to some extent, thus this timeliness makes the real cold chain demand and supply keep in good pace with real market. With information communication between supermarkets and suppliers, suppliers would realize the real demand of downstream consumers and keep their inventory level in a suitable level.

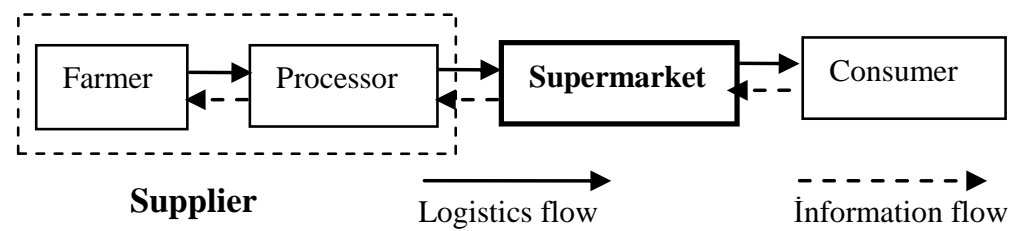

Figure 2. The SS Mode of ACC

Another benefit of this mode is for consumers. With the intermediary part dropped, end consumers would get their favorite produce at cheaper price [13]. Take Yonghui Supermarket as example, this company, founded in 2001, one of the top 500 enterprises in China and national "circulation" and "agricultural industrialization" leading enterprises, is the first batch of circulation enterprises in mainland China to integrate modern supermarket with fresh agricultural products.

Yonghui Supermarket focus on Chinese agricultural products and food industry, and adhere to the concept of "sharing fusion" and "development with competition" in order to create an agricultural product cold chain blue ocean. Yonghui supermarket currently operates in 17 provinces and municipality cities as Fujian, Zhejiang, Guangdong, Chongqing, Guizhou, Sichuan, Beijing, Shanghai, Tianjin, Hebei, Anhui, Jiangsu, Henan, Shaanxi, Heilongjiang, Jilin and Liaoning, with nearly 500 chain stores, more than 4 million square meters and ranked NO.8 in top chain enterprises of China in 2015, according to the official reports from the website of Commerce department of China.

Though its centralized purchasing model, Yonghui keeps long-term relationship with strategic suppliers and focuses on regional concentration ratio. Yonghui intensifies agriculture-supermarket jointing project to reduce cold chain links and logistics cost, and establishes a typical SS model of ACC which executes quick-response mechanism and shortens lead-time of cold chain.

\subsection{SDC Model}

SDC model exists in China where S, D, C respectively represent supplier, distribution center and consumer as shown in Figure3. In this model, the main operation powers are exercised by food processors like milk companies which prefer to operate by their own. They establish and manage their own cold chain logistics system. With the advancement of information technology, suppliers, especially food processors, prefer to directly seek the eventual consumers.

These companies collect demand information online and trigger the process of cold chain activities [14]. Distribution centers, including central and regional distribution centers (CDC/RDC), are totally operated by their own or sometimes outsourced to TPL (third party logistics) companies. TPLs would evolve as FPL (fourth party logistics) provided that they integrate information and are able to present the comprehensive solution for their customers. 


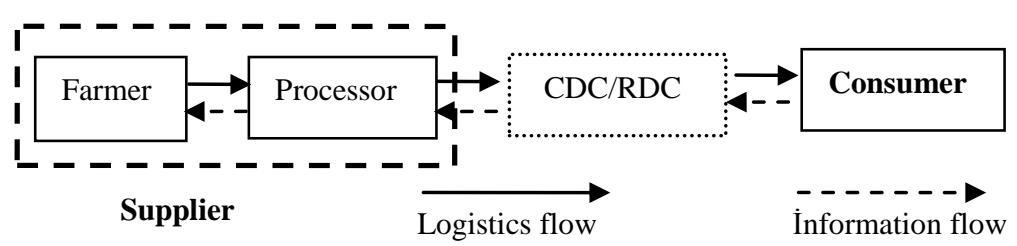

Figure 3. The SDC Mode of ACC

Take Heilongjiang province as example. At present, in Heilongjiang, there are some slaughtering processing enterprises which tend to make vertical integration. They not only establish farms or breeding base by their own upward the supply source in order to guarantee the living quality and safety of the materials, but also operate many self-built terminals stores and cold chain logistics, store, transport and sell their slaughtered processing products. Some of them foster their famous brand such as "Beidahuang", "Shuanghui", "Yurun", "Jin Luo" and so on.

It is notable that some companies exercise $\mathrm{O} 2 \mathrm{O}$ (online to offline) strategy to enrich customers' personal experience and encourage them to put on orders with bonus. These $\mathrm{O} 2 \mathrm{O}$ projects are prevailing currently and loads of capital invested. Besides a sort of brand new marketing idea to connect and engage with end consumers online and attract them to experience in their physical premises, it is really a good supply chain idea which means the collected information flow would be well integrated with physical logistics flow as shown in the figure.

Although tons of capitals have been invested in variable $\mathrm{O} 2 \mathrm{O}$ cold chain projects currently, SDC model is not dominant, so we here merely analyze SWR and SS models.

\section{Systematic Dynamic Model of ACC}

\subsection{System Modeling Description}

Here we plan to model whole system in order to compare the bullwhip effects, inventory levels and their fluctuation under stochastic demand between SWR mode and SS models.

As discussed above, the mental model of SWR is that all chain members engage in their own business, and they place their order according to their own perception of market forecasting rather than other members' information like their total inventory levels and demand estimates.

This is the real situation what most markets are. Mental SS model, however, is that the suppliers (processors), with consideration of the inventory of retailers (supermarkets), and engage in replenishment for the downstream chain members through some mechanism. This similar relationship between supplier and retailer is called VMI, like typical Nestle and Carrefour case in many supply chain textbooks, which means it is the vendor that manages inventory. This good concept is to decrease the bullwhip effects, minimize inventory levels and keep efficient communication between supply chain members including all participants.

Bullwhip effect refers to such an distribution channel phenomenon in which estimates result in supply chain inefficiencies [7]. Bullwhip effect is also known as the Forrester Effect, for the concept first appeared in Jay Forrester's Industrial Dynamics (1961) and in the 1990s, Hau Lee, a Professor of Stanford University, helped incorporate the concept into supply chain vernacular using a story about Volvo [8].

If looking at chain further back in the supply chain for a product, the demand would be found amplified upward the supply chain, this larger and larger swings in inventory level result from mere little changes in demand from end users. 
The plots of the fluctuating demand look like a whip, which is why the name for the effect called the bullwhip effect. The further from the originating signal, the greater the distortion of the wave pattern. In a similar manner, forecast accuracy decreases as move upstream along the supply chain [14-15]. This signal becomes more and more chaotic and unpredictable as moving away from consumer purchasing behavior [16-17].

SWR model consists of three agents, namely, supplier, wholesaler and retailer. There are only two agents in SS model, supplier and supermarket. For the system interface of them both model begins from the supplier and end at end user.

\subsection{Detailed System Flowcharts}

In the SWR model, three inventory levels are shown as in Figure 4 where the wholesalers (shown as distributors in figure) play key role in the chain. From the business process, interaction of information, logistics and agents are set.

Table1 figures out the math and logic formulas. As the traditional circulation method, the suppliers (shown as dealers in figure), as farmers and/or processors would not care about the inventory level of downstream wholesalers (distributors) and retailers, similarly, other agents merely focus on their own. Meanwhile, this model fails to share the knowledge of supply and demand, which makes isolated island of information true in the chain. With symmetric information suppliers (dealers) are little possible to make wise decisions, which facilitates the fluctuation of common production and price.

In the SS model, as this argument goes, there are two inventory levels as the supplier inventory and supermarket inventory. This model makes information sharing, which is the great benefit.

Suppliers would make sense of the inventory level of supermarkets, thus make timely replenishment according to the real-time sale data and physical volume of inventory of supermarkets. This model inhibits the bull-whip effect of ACC as low as possible. Figure 5 illustrates the detailed flowchart and Table 2 shows the mathematical and logic formulas.

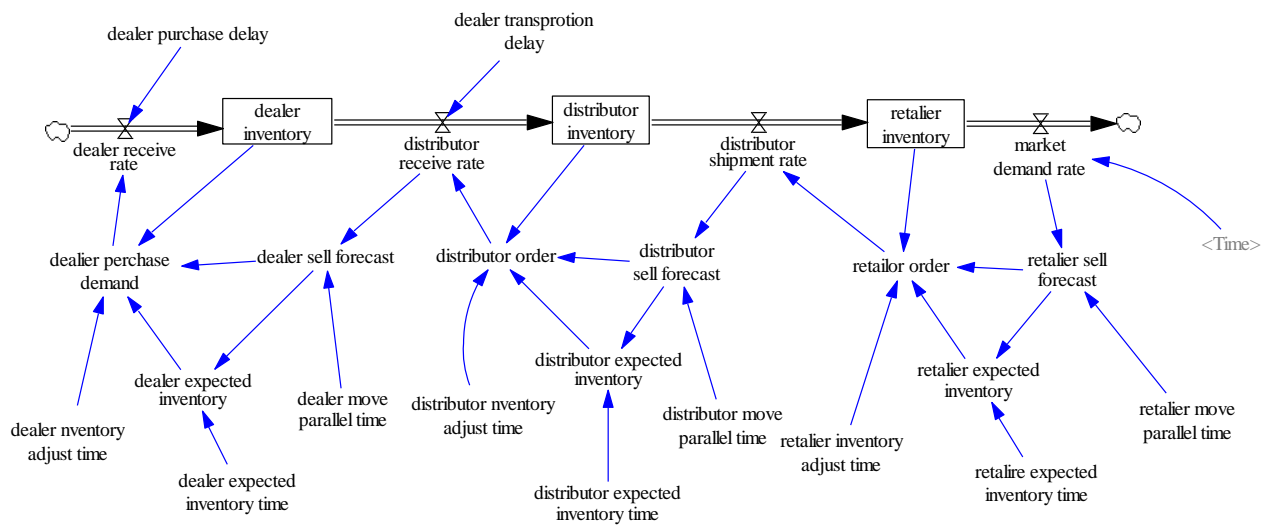

Figure 4. The SWR Model Flowchart

Table 1. Main Mathematical Formula of SWR Model

\begin{tabular}{|l|l|}
\hline Variables & \multicolumn{1}{|c|}{ Mathematical or Logic Formula } \\
\hline $\begin{array}{l}\text { Retailer } \\
\text { Order }\end{array}$ & $\begin{array}{l}\text { MAX }(0, \text { Retailer Sale Forecast }+(\text { Retailer Expected Inventory - } \\
\text { Retailer Inventory }) / \text { Inventory Adjust Time })\end{array}$ \\
\hline $\begin{array}{l}\text { Wholesaler } \\
\text { Order }\end{array}$ & $\begin{array}{l}\text { MAX }(0, \text { Distributor Sale forecast + (Distributor Expected } \\
\text { Inventory - Distributor Inventory }) / \text { Inventory Adjust Time })\end{array}$ \\
\hline $\begin{array}{l}\text { Supplier } \\
\text { Demand }\end{array}$ & $\begin{array}{l}\text { MAX(0, Dealer Sale Forecast + (Dealer Expected Inventory }- \\
\text { Dealer Inventory }) / \text { Inventory Adjust Time })\end{array}$ \\
\hline
\end{tabular}




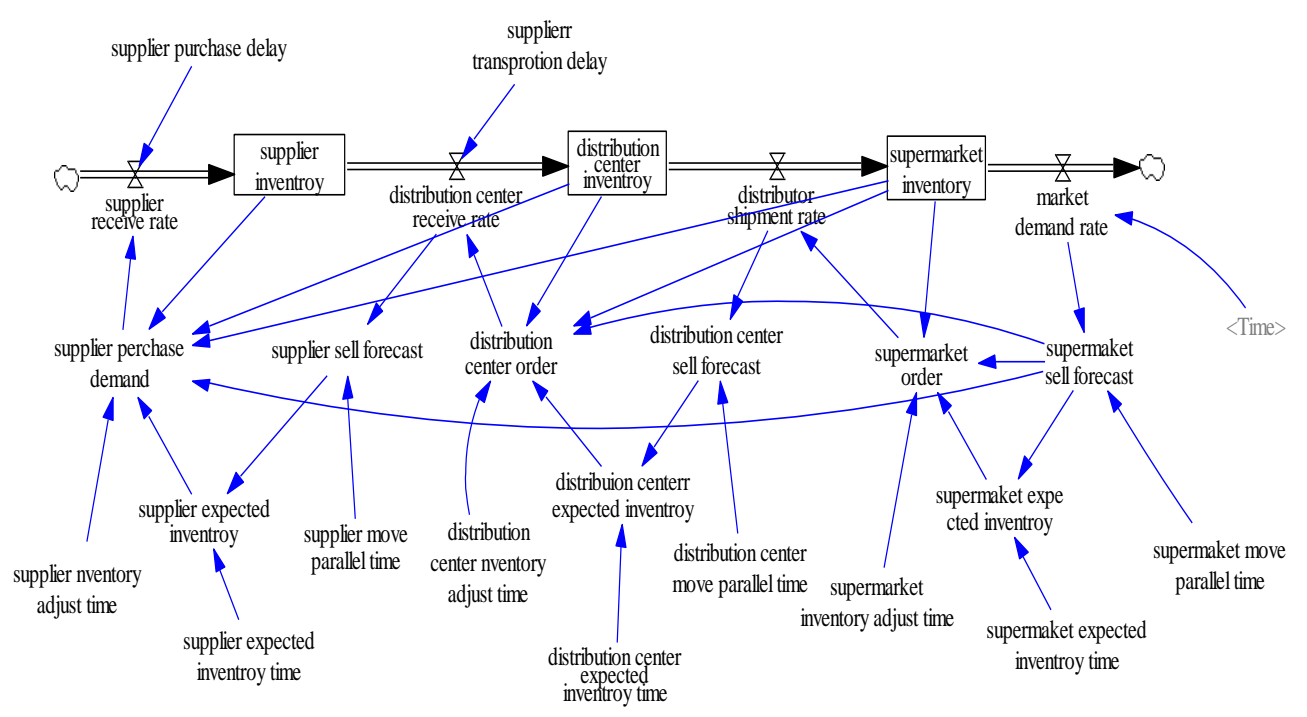

Figure 5. SS Model Flowchart

Table 2. Main Mathematical Formula of SS Model

\begin{tabular}{|l|l|}
\hline Variables & \multicolumn{2}{|c|}{ Mathematical or Logic Formula } \\
\hline Retailer & $\operatorname{MAX}(0, \quad$ Retailer Sale Forecast + (Retailer Expected \\
Order & Inventory - Retailer Inventory $) /$ Inventory Adjust Time $)$ \\
\hline $\begin{array}{l}\text { Supplier } \\
\text { Order }\end{array}$ & $\begin{array}{l}\text { MAX }(0, \quad \text { Supermarket Forecast }+ \text { (Supplier Expected } \\
\text { Inventory } \times 2-\text { Supplier Inventory }- \text { Supermarket } \\
\text { Inventory }) / \text { Inventory Adjust Cycle })\end{array}$ \\
\hline
\end{tabular}

\section{Simulation and Results}

\subsection{Setting Parameters}

The purpose of system modeling is to analyze the bullwhip effects and relevant inventory level of the two models before running them. We set related parameters and initial values of variables. SD is a good experiment space for making management decisions, by which we can choose variable scenarios, concepts and tactics to readjust the optimization of demand parameters [12]. Comparing other modeling and simulation methods, it is rather simple to obtain the equation solution. Table 3 lists related parameters and initial values of variables for model simulation.

\section{Table 3. Parameters and Initial Values of Variables for Simulation}

\begin{tabular}{|l|c|}
\hline $\begin{array}{l}\text { Variables } \\
/ \text { Parameter }\end{array}$ & Initial Value/ Instructions \\
\hline $\begin{array}{l}\text { Retailer } \\
\text { (Supermarket) }\end{array}$ & Retailer Inventory $=\begin{array}{c}3000 \mathrm{Kg}, \text { Supermarket Inventory }= \\
\text { Inventory } \\
\text { Level }\end{array}$ \\
\hline $\begin{array}{l}\text { wholesaler } \\
\text { Inventory } \\
\text { Level }\end{array}$ & wholesaler Inventory $=3000 \mathrm{Kg}$ \\
\hline $\begin{array}{l}\text { Supplier } \\
\text { (dealer) } \\
\text { Inventory }\end{array}$ & Dealer Inventory $=3000 \mathrm{Kg}$, Supplier Inventory $=3000 \mathrm{~kg}$ \\
\hline
\end{tabular}




\begin{tabular}{|l|c|}
\hline Level & \\
\hline Market & 1000+IF THEN ELSE (Time $>4$, RANDOM NORMAL(- \\
Demand Rate & 200, 200, $0,100,4), 0)$ \\
\hline $\begin{array}{l}\text { Simulation } \\
\text { Running Time }\end{array}$ & 200 Days $; \mathrm{dt}=1$ \\
\hline
\end{tabular}

\subsection{Simulation under Stochastic Demand}

We run the models of SWR model and SS model under stochastic demand, stochastic demand reflects the uncertain, variable and dynamic characteristics of real situation of the market. This simulation environment maintains the meaningful results. Figure 6 demonstrates the demand and inventory levels of agents in the two models. It is obvious that demand order of supermarket (retailer), wholesaler (distributor) and supplier dealer) all represent some nonlinear trend which would be enlarged with the order demand of end user and suppliers. As the added node of ACC, the larger the fluctuation gets, the more and more obvious the bull-whip effect tends to be. Note that we define the quantifiable bull-whip effect (BE) with the ratio of standard deviation (SD) of upstream agent's order and downstream agents' demand as follows:

$$
B E=\frac{S D(\text { up.order })}{S D(\text { down.demand })}
$$

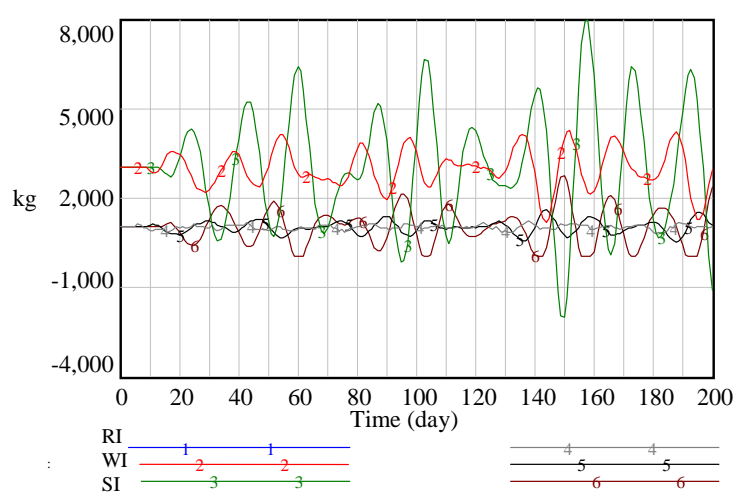

(a) Inventory and Demand in SWR Mode

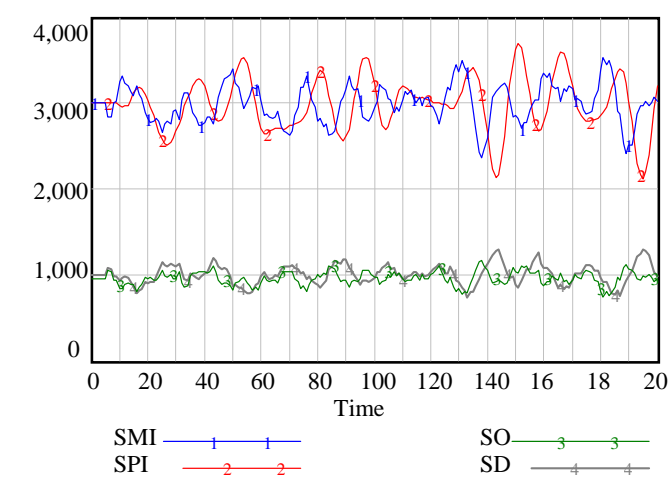

(b) Inventory and Demand in SS Model

Figure 6. Inventory and Demand Changes by ACC Model 
In Figure 6(a), the number of 1,2,3 means the inventory change of retailer (RI) , Wholesaler (WI) and supplier (SI), which show complicated nonlinear output with fluctuation. 4, 5, 6 means retailer order (RO), wholesaler order (WO) and supplier demand (SD). On the other hand, in Figure 6(b), the inventory changes of supermarket(SMI,1) and supplier (SPI, 2) are not as significant as the former.On the other hand, line 3 and 4 represent respectively supermarket order (SMO) and supplier demand (SD).

Data analysis are showed in Table 4, comparing with SWR model, SS model of ACC has less bull-whip effect of supplier by $224.63 \%$, lower inventory level at $2.63 \%$ and the total inventory fluctuation minimized at $612.50 \%$. Simulation results show SS model is more efficient and effective agricultural product.

\section{Table 4. Changes in Inventory Level and Demand Response by Models of} ACC

\begin{tabular}{|c|c|c|c|c|c|}
\hline \multicolumn{3}{|c|}{ SWR Mode } & \multicolumn{3}{|c|}{ SS Mode } \\
\hline \multirow{2}{*}{$\begin{array}{c}\text { Retailer } \\
\text { Demand } \\
\text { Order }\end{array}$} & Mean & 999.3832 & \multirow{2}{*}{$\begin{array}{l}\text { Supermarket } \\
\text { demand order }\end{array}$} & \multirow{2}{*}{$\frac{\text { Mean }}{\mathrm{SD}}$} & \multirow{2}{*}{$\frac{999.3832}{78.9200}$} \\
\hline & SD & 78.9200 & & & \\
\hline \multirow{3}{*}{$\begin{array}{l}\text { Retailer } \\
\text { Inventory }\end{array}$} & Mean & 2995.8 & \multirow{3}{*}{$\begin{array}{l}\text { Supermarket } \\
\text { inventory }\end{array}$} & Mean & 2995.8 \\
\hline & SD & 224.0098 & & $\mathrm{SD}$ & 224.0098 \\
\hline & $\mathrm{BE}$ & 0.9396 & & $\mathrm{BE}$ & 0.9396 \\
\hline \multirow{2}{*}{$\begin{array}{c}\text { Wholesaler } \\
\text { Demand } \\
\text { Order }\end{array}$} & Mean & 1003.9 & \multirow{2}{*}{$\begin{array}{c}\text { Supplier } \\
\text { demand order }\end{array}$} & Mean & 1002.1 \\
\hline & SD & 210.9395 & & $\mathrm{SD}$ & 114.4828 \\
\hline \multirow{3}{*}{$\begin{array}{l}\text { Wholesaler } \\
\text { Inventory }\end{array}$} & Mean & 2976.6 & \multirow{3}{*}{$\begin{array}{l}\text { Supplier } \\
\text { inventory }\end{array}$} & Mean & 2985.1 \\
\hline & SD & 642.3820 & & SD & 313.6183 \\
\hline & $\mathrm{BE}$ & 2.5139 & & $\mathrm{BE}$ & 1.3630 \\
\hline \multirow{2}{*}{$\begin{array}{c}\text { Supplier } \\
\text { Demand } \\
\text { Order }\end{array}$} & Mean & 1009.7 & \multirow{2}{*}{$\begin{array}{l}\text { Customer } \\
\text { demand }\end{array}$} & Mean & 999.6954 \\
\hline & SD & 296.4322 & & $\mathrm{SD}$ & 83.9932 \\
\hline \multirow{3}{*}{$\begin{array}{l}\text { Supplier } \\
\text { Inventory }\end{array}$} & Mean & 3063.5 & \multirow{3}{*}{\multicolumn{3}{|c|}{$\begin{array}{c}\text { Note: SD - Standard Deviation } \\
\text { BE - Bull-whip Effect }\end{array}$}} \\
\hline & SD & 1920.9 & & & \\
\hline & $\mathrm{BE}$ & 3.5293 & & & \\
\hline
\end{tabular}

\section{Conclusion}

Due to the lack of efficient cold chain logistics process, Chinese agricultural postpartum loss are severe, and frequent food safety accidents occur. agricultural product cold chain encompasses the planning and management of all activities involved in sourcing and procurement, conversion, and all logistics management activities of the perishable produce under suitable condition for the purpose of meeting customers' demand, which is deemed as a chain structure with suppliers, intermediaries, wholesalers and all sorts of retailing terminals, third party service providers, and the end customers.

An efficient agricultural product cold chain would keep the fresh produce in good condition and pass on the real value to through the whole chain till the end consumer. How to operate an efficient and cost-effective agricultural cold chain has become a hot issue of the whole society in China.

This study aims to analyze the agricultural product cold chain inventory based on system dynamics theory and modeling method. Currently, Chinese agricultural product cold chain falls into three primary models in which key chain member dominate chain efficiency. Among them, SWR model (suppliers-wholesalers-retailers) is controlled by the wholesalers. SS model (suppliers-supermarkets) is dominated by the retailer 
(supermarket). The third one is SC model (suppliers-consumers), where suppliers control the efficiency. Due to the immaturity in Chinese cold chain practice, we shed light on the first two operation models.

Two main models to operate agricultural product cold chain are proposed and compared. Simulation results show SS model has lower inventory level (at 2.63\%), less inventory fluctuation (minimized at $612.50 \%$ ) and bull-whip effect decreased (by $224.63 \%$ ). In this more efficient and effective model, agricultural product cold chain demonstrates better market adaptability and related idea of quick response, and obtains comparative advantage to traditional SWR mode.

System dynamics, to some extent, present an effective method to analyze the complicated dynamics of supply and demand process of agricultural product cold chain. Also admittedly, this research has its limitations that we only consider the relationship of total inventory and order, and did not analyze the implication of order processing time to inventory level. Another space to research is the how SC model operate under $\mathrm{O} 2 \mathrm{O}$ tendency and big data circumstance, which we fail to analyze according to the current practice. However, with the development of the integration of agriculture with internet finance and supply chain finance, this model would evolve to an operation models we cannot ignore in the near future. Last but not least, other impacting factors would play some roles. All these outstanding understanding need to research further in the future.

\section{Acknowledgment}

This work is supported by Humanities and Social Science Research Project of Ministry of Education, P.R. China (No.13YJA630139) and Doctorial Research Initiation Funds of Shanghai Ocean University.

\section{References}

[1] S. Xin, L. Qiao and Z. Dawei, "Evaluation on regional agricultural product Cold Chain Logistics Competitiveness", Journal of Applied Sciences, vol. 13, no.14, (2013), pp. 2670-2675.

[2] J. W. Park and J. C. Lee, "A Study on Agricultural Supply and Demand, Stabilizing the Model using the NFC", International Journal of u- and e- Service, Science and Technology, vol. 9, no. 2, (2016), pp. 309318.

[3] I. Ozimek and S. Z. Biemans, "Determinants of Polish consumers' food choices and their implication for the national food industry", British Food Journal, vol. 133, no. 1, (2011), pp. 125-145.

[4] X. Zhang and G. Chen, "The Selection on Operation Models of Agricultural Product Supply Chain in China", China Circulation Economy, vol. 10, (2009), pp. 57-60.

[5] R. Montanari, "Cold chain tracking: a managerial perspective", Trends in Food Science \& Technology, vol. 19 , no. 8, (2008), pp. 425-431.

[6] O. Ahumada and J. R. Villalobos, "Application of planning models in the agricultural product supply chain: A review”, European Journal of Operational Research, vol. 4, no. 2, (2009), pp. 1-20.

[7] L. B. Robert and H. Mendelson, "Information transmission and the bullwhip effect: An empirical investigation", Management Science, vol. 58, no. 5, (2012), pp. 860-875.

[8] P. Brauner, S. Runge, M. Groten, M. Schuh and M. Ziefle, "Human Factors in Supply Chain Management", Lecture Notes in Computer Science, vol. 8018, (2013), pp. 423-432.

[9] S. Cannella and E. Ciancimino, "On the bullwhip avoidance phase: supply chain collaboration and order smoothing", International Journal of Production Research, vol. 48, no. 22, (2010), pp. 6739-6776.

[10] W. Herlyn, "The Bullwhip Effect in expanded Supply Chains and the Concept of Cumulative Quantities”, epubli Verlag, Berlin, S. 513-528, ISBN 978-3-8442-9878-9, (2014).

[11] L. Gui, Z. W. He, and L. J. Zhao, "Construction of agricultural product Logistics Information Platform in Beijing", Wuhan: Hubei Peoples Press, (2013), pp. 1015-1018.

[12] Y. Bo, S. Song and Y. Bing, "Sustainable development of the fresh agricultural products supply chain through the application of RFID technology", Information Technology \& Management, vol. 16. (2015), pp. 67-78.

[13] Y. Han and J. Yang, "The Study on the Ally of Agricultural Product Supply Chain Dominated by Wholesalers", Beijing Industrial and Commercial University Xuebao(Social Science), vol. 25, no. 3, (2010), pp. 27-31. 
[14] Z. Shuang and X. Zheng, "The analysis on the New Agricultural Products Circulation Model Based on Direct Connection of Farmers and Supermarkets", Anhui Agriculture Science, vol. 38, no. 22, (2010), pp. 12212-12214.

[15] J. Blandon, S. Henson and T. Islam, "The Importance of Assessing Marketing Preferences of Smallscale Farmers: A Latent Segment Approach", European Journal of Development Research, vol. 22, (2010), pp. 494-509.

[16] M. Zhang, "Agricultural Supply Chain Operation Models and Produce Quality. Rural Economics", vol. 8, (2010), pp. 101-108.

[17] J. Liu, J. Ma and Y. Tian, "The Analysis of Agricultural Output in Port SD Province Based on System Dynamics", International Journal of u- and e- Service, Science and Technology, vol. 8, no. 9, (2015), pp. 91-102.

\section{Authors}
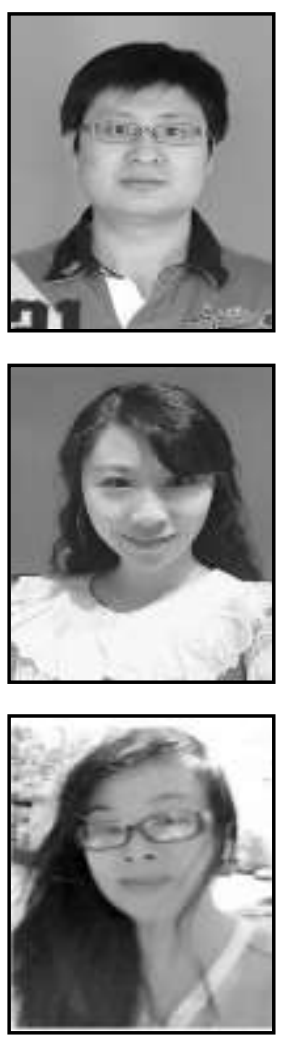

Xin Shen, he is an Associate Professor at the College of Economics and Management, Shanghai Ocean University. He focuses on the research of service science and management.

Qiao Liu, she is a Lecturer, Heilongjiang Institute of Technologies, doctor candidate of Harbin University of Science and Technologies. She focuses on the research on logistics and supply chain management.

Dawei Zhao, she is a Professor, Management School, Harbin University of Science and Technologies. She focuses on the research of logistics and supply chain management. 
International Journal of $\mathrm{u}-$ and $\mathrm{e}-$ Service, Science and Technology Vol. 10, No. 6 (2017) 